Yates, N., Stanger, S., Wilding, R. and Cotton, S., Approaches to assessing and minimizing blood wastage in the hospital and blood supply chain,

ISBT Science Series,

Volume 12, Number 1, Pages 91-98. ISSN 1751-2824,

http://dx.doi.org/10.1111/voxs.12330, doi: 10.1111/voxs.12330.

\title{
Approaches to Assessing and Minimising Blood Wastage in the Hospital and Blood Supply Chain
}

Dr. Nicola Yates ${ }^{a}$, Dr Sebastian Stanger ${ }^{a}$, Prof. Richard Wilding ${ }^{a}$ and Sue Cotton ${ }^{b}$

${ }^{a}$ Cranfield School of Management, ${ }^{b}$ NHSBT

Short title: Minimising Blood Wastage

Address: Cranfield School of Management, Cranfield University, Cranfield, Bedfordshire, MK43 OAL, UK

Tel: +44 (0) 1234758012

Email: nicky.yates@cranfield.ac.uk

Published by Wiley. This is the Author Accepted Manuscript issued with:

Creative Commons Attribution Non-Commercial License (CC:BY:NC 3.0).

The final published version (version of record) is available online at DOI: 10.1111/voxs.12330.

Please refer to any applicable publisher terms of use. 


\begin{abstract}
Despite the scale of blood usage worldwide, blood remains a scarce and precious resource. As with any perishable product careful management of inventories to minimise wastage is crucial. However, due to the nature of the supply of blood, wastage is not only an economic issue as every unit wasted, squanders the time and effort of the human donor. Blood inventory management is therefore a tradeoff; ensuring $100 \%$ availability of all blood products at all times whilst minimising wastage.

Hospitals are at the front line of blood use and are the location where much blood is wasted. Inventory management practises in hospital transfusion laboratories are critical. Much of the extant literature in this area posits that good management of hospital blood inventories is due to sophisticated inventory models and algorithms. However, recent research has found that good management practises are much more important. The drivers for low wastage and good inventory management practise can be described using 6 key themes.

Blood supply chain management is much more than managing wastage in hospitals. Proper management of the supply chain as a whole can lead to significant reductions in blood wastage. Recent research has found that methods commonly used in commercial supply chain management can lead to efficiencies in the blood supply chain context. An example of this is stock sharing or lateral transhipment of blood units close to expiry between hospitals, reducing wastage across the supply chain.
\end{abstract}




\section{Introduction}

Despite the scale of blood usage worldwide, blood remains a scarce and precious resource [1-4]. Blood inventory management is both challenging and crucial; ensuring availability whilst at the same time minimising wastage [5 - 7]. Due to the nature of the supply of blood, wastage is not only an economic issue but has a normative societal impact. Every unit wasted, squanders the time and effort of the human donor, which in many countries is made on an entirely voluntary basis [8]. Blood inventory management is therefore a trade-off; ensuring $100 \%$ availability of all blood products at all times whilst minimising wastage, in the context that the consequence of a stock out could be fatal. Wastage can occur at many points across the blood supply chain [5, 9]; however, in the United Kingdom and Germany, in recent years, wastage in hospitals has been found to be significantly higher than in blood centres.

Reducing wastage is contingent on good blood inventory management. Research in this area goes back to the early 1960 s $[10,11]$. There have been two major periods of activity:

1. 1970s, where regression models were first developed to identify optimal stock levels and order quantities.

2. 2000s, which have been dominated by more advanced Operations Research techniques and Simulation.

Significant works from the first period start with Jennings [12] who described the fundamentals of how the blood supply chain operates and identified the three key measures of performance: shortage, outdating/wastage and the cost of information and transportation. Brodheim et al. [13] developed an inventory model based on the average age and average wastage of blood units using a Markov chain approach. Cumming et al. [14] subsequently developed a planning model for the collection of donations and a basic model for issuing units to hospitals. Prastacos and Brodheim $[15,16]$ published a prototype computer-based regional distribution model implemented in the USA called Programmed Blood Distribution System (PBDS). Taking a different approach, Cohen and Pierskalla [17] developed target stock levels for hospital blood banks derived from data provided by one hospital and one blood centre.

There is then a gap of nearly 20 years before Owens et al. [18] analysed the impact of the average age of units on inventory performance. They found that the average age varied from blood group to blood group, concluding that an extension of shelf life had the potential to yield significant reductions in wastage. Hence inventory management is not the only factor that has an impact on wastage. 
The establishment of the Blood Stocks Management Scheme (BSMS) in the United Kingdom and the instigation of a large database monitoring stock levels and wastage rates in hospitals and blood centres has opened new possibilities in blood inventory management research [19]. The availability of these new data has led to greatly improved transparency and consequently an increased understanding of blood inventory management and improved visibility of the blood supply chain. This increased data availability which is mirrored in many other countries has been coupled with improvements in computer technology, which have led to the availability of simulation tools with sufficient power to build meaningful models of this extremely complicated process. Various studies employ simulation techniques (such as discrete event simulation and level crossing techniques), concluding that simulation can inform and reduce risks associated with blood supply chain changes and decisions [20-22]. A recent study by Perera et al [23] surveyed 265 UK hospitals; identified a number of additional factors for efficient inventory management. The research showed that reducing the reservation period for reserved units (assigned inventory) leads to lower inventory levels and reduced wastage.

The literature on blood inventory management is rather limited. However, blood with its limited and strictly monitored shelf life is an example of a perishable product, other sectors also have to contend with similar problems and issues. Some techniques used in industrial environments, e.g. just in time, are not suitable for the blood supply system due to the consequences of an inventory shortage [24], however others are applicable. A review of these models can be found in [25]. On reviewing these models Stanger et al [25] find that due to the added complexity of the presence of both assigned and unassigned inventory, most of the general models from perishable inventory theory discussed are not applicable.

The research to date in blood inventory management is dominated by operations research specialists who develop mathematical models and use them to derive policies [15, 17, 22, $26-28]$. On the one hand literature creates the impression that the application of complex inventory models leads to low wastage levels and good inventory performance [26, 29-31]. However, critics state that these models are too complex and approximations and heuristics are a more fruitful way to good performance in perishable inventory systems $[7,32-34]$. This paper will explore these issues in the context of the UK blood supply chain.

\section{Measuring Wastage}

In order to effectively manage and reduce wastage, it is important to measure and record it. Visibility of wastage levels is crucial, without this it is impossible to control and minimise them. Therefore, wastage must be measured and not only at an overall level; visibility of wastage by blood product and blood group is essential [35]. The BSMS was set up for this purpose [24]; and has been successfully 
doing this in England and North Wales for many years. A useful Key Performance Indicator (KPIs) is Waste as a Percentage of Issues (WAPI). WAPI is a metric compiled of different types of wastage (time expiry, out of temperature control, refrigerator failure, and miscellaneous) and is calculated as follows:

$$
\text { WAPI }(\text { in } \%)=\frac{\text { sum of wasted blood units for time } t}{\text { sum of blood units issued to the hospital for time } t} \times 100
$$

WAPI shows the percentage of units wasted over the period analysed: the lower the ratio, the better the performance. It provides a comparable metric independent of the hospital type and size. WAPI is widely used to monitor wastage within hospitals but also to compare and rank hospitals and to monitor the system as a whole [9, 25 \& 37]. In the UK both system wide wastage and WAPI have been decreasing in recent years, see Figure 1 . The ability to measure this wastage has had an important part in this improvement.

An alternative and more novel measure is WAASL, wastage as percentage of average stock level, a measure of wastage by time expiry as the percentage of the average stock level (ASL) in the hospital or blood centre and is defined as:

$$
\text { WAASL }(\text { in } \%)=\frac{\text { sum of wasted blood units for time } t}{\text { average number of units in stock in the hospital over time } t} \times 100
$$

A low WAASL value means that the stock is used effectively to satisfy the demand and there is less chance of the stock being wasted. The most prevalent and important cause of blood wastage from an inventory management perspective, is due to time expiry of units at the end of their shelf life.

\section{Blood Wastage in Hospitals}

Hospitals are at the front line of blood use and are the location where much blood is wasted. Inventory management practises in hospital transfusion laboratories are critical. Much of the extant literature in this area posits that good management of hospital blood inventories is due to sophisticated inventory models and algorithms. However, recent research has found that, in the UK at least this is not the case and that good management practises are much more important. The studies of Stanger et al $[25,38]$ highlight these practises through interviews with blood inventory managers in a set of selected top performing hospitals. These revealed 6 key themes that together drive good performance in blood stocks inventory management. These themes are human resources and training, stock levels and order patterns, transparency of inventories, simple inventory procedures, focus on freshness, and internal collaboration within the hospital. These themes are now discussed, this is adapted from [25, 38]. 
The study found that experienced and skilled staff are the key to low wastage. Educating transfusion laboratory staff, thereby increasing the level of awareness of what good blood inventory management means, is an essential element of good performance. Regular staff training and briefings together with the use of detailed and up to date SOPs (Standard Operating Procedures) is essential. An SOP comprises a detailed description of a process; they ensure that staff execute the process correctly as confirmed in previous work [23,39]. It is important to ensure that staff handling critical processes, such as ordering and issuing, are trained regularly and that fluctuation and rotation rates in these staff positions are kept low. The experience of staff was also found to impact on performance.

Another key element is ensuring that staff are aware of the impact of wasting a unit of blood. If staff understand the wider implications of wasting a unit of blood, such as cancellation of treatments, the financial and operational impact, and the moral duty toward the donors, they are then motivated to make better decisions. Staff must be aware of the impact of their decisions on the whole blood supply chain and the wider implications of them beyond their hospital. The system is very complex and dynamic and as such, a wrong decision can have a serious effect. There is a synergy here with patient blood management (PBM). A key enabler of PBM is the transfusion safety officer or transfusion liaison nurse who promote safer and more effective transfusion practise and act as a bridge between the laboratory and clinicians [40]. Reducing wastage is one of the many responsibilities of this role, capitalising on this and making these people inventory champions or even introducing a parallel role with inventory knowledge, visibility and responsibility has the potential to reduce wastage further.

\section{Stock Levels and Order Patterns}

Contrary to what is claimed in the academic literature on perishable inventory management [22, 29-31] it is not complex models, algorithms and equations, rather simple procedures or approximations $[7,32,33]$ that drive performance. In all of the hospitals the stock levels have evolved over many years of continuous adjustment. They are based on experience and developed by making small incremental changes to achieve optimal levels. However, levels are not entirely rigid with hospitals adjusting them dynamically on a daily basis; experience and good estimations are the rationale behind these changes not complex models. Levén and Segerstedt [41] found similar approaches in capacity planning for frozen storage, where simple analytical models and heuristics were preferred over complex and exact models.

Good decision making is again vital in this case; which is contingent on access to information (e.g. inventory levels and planned surgeries) at the right time, and also the necessary skills and 
experience to judge the information. Daily orders are adjusted based on the number of scheduled surgeries and recurring top-up transfusions.

Order patterns also have a major impact on wastage. When large quantities of blood are required, a number of smaller orders rather than a single large order can be worthwhile. This prevents delivery of large numbers of units with the same expiry date and increases flexibility. This is another area where a transfusion liaison role could be employed to great effect capitalising on visibility of both available inventory and clinical requirements to inform decisions.

\section{Transparency of Inventories}

Transparency of inventory is a key lever for low wastage, as better information about the locations and quantities of blood components in the hospital leads to more accurate decisions about order quantities and hence lower wastage. It is vital that inventory levels are checked frequently. Having transparency in all inventory locations and knowledge of the status of all stock keeping units (SKUs) in all inventory locations, especially assigned inventory, is essential. However, benefits can only be derived from this information if it is used properly in the ordering process.

\section{Simple inventory procedures}

In contrast to the discussions within the academic literature, simple "rule of thumb" inventory procedures are important to success. These include a "standing order" (a fixed order which will be fulfilled by the blood service automatically) for hospitals which receive more than one delivery per day. This reduces complexity and workload whilst ensuring blood supply, but allows flexibility to react to changes in demand with a second order later in the day. Other approaches include the use of red cards, a visual aid to highlight units close to expiry, reducing the storage capacity of fridges so they do not appear empty and attaching labels to the front of fridges highlighting the target and minimum stock levels along with other order information. All these procedures serve to prevent unnecessary panic orders of blood from the blood service.

\section{Focus on Freshness of Stock}

Another key device for reducing wastage is keeping the stock as fresh as possible. Using a strict "oldest unit first out" (OUFO) policy or "first in first out" (FIFO) policy was seen as the most important discipline in reducing wastage. All hospitals sort their inventories in the fridges by remaining shelf-life so that the oldest units were at the front of the shelves. These findings confirm the work of Owens et al. [18] who demonstrated a relationship between shelf life and inventory performance. 
Hospitals use the blood centre stock level data provided by NHSBT. As blood centres work on a strict FIFO policy, high stock levels indicate that a blood centre is currently issuing older blood. Hospitals adjust their order patterns dynamically to account for this.

\section{Internal Collaboration within the Hospital}

Improving collaboration within a hospital has a huge potential for reducing wastage. Motivating staff to share information and collaborate leads to lower wastage rates and increased flexibility in the transfusion laboratory. By collaboration with key stakeholders it is possible to reduce just-in-case orders and hence wastage. A reduction in just-in-case requests increases flexibility in using and allocating available units to other patients without wasting valuable shelf life when units are in the assigned inventory. As already confirmed by Perera et al. [23], a reduction in the reservation time for assigned units improves performance; hence, focusing on a minimisation of the assigned inventory is an important factor. In order to do so, some hospitals adjust orders and requests according to their predefined "maximal surgical blood ordering schedule" (MSBOS), which defines the maximum number of units issued for each surgical operation. This is in line with good practice in retailing of fresh produce, where so called "partnershipping" with the supplier leads to improved performance [42].

\section{Summary}

The discussion of all six themes highlights the importance of having high-quality, trained, and experienced staff. These staff must be aware of the wider implications of wasting a unit of blood, be able to apply simple inventory management techniques, and collaborate with clinical staff outside of the hospital laboratory. The lessons learnt for practice can be summarised in the following six points:

1 Ensure you use experienced staff and train them.

2 Understand target stock levels and order patterns.

3 Create and maintain transparency of inventories.

4 Keep inventory procedures simple.

$5 \quad$ Keep stock fresh and monitor remaining shelf life.

6 Collaboration across the business is critical to success.

\section{Blood Wastage across the Supply Chain}

Blood supply chain management is much more than managing wastage in hospitals. Proper management of the supply chain as a whole can lead to significant reductions in blood wastage. Recent research has found that techniques from commercial supply chain management can be employed to great effect in the blood supply chain [43]. Many of these are based on collaboration, a 
key factor as already discussed in this paper. One example of such a technique is lateral transhipments or stock sharing of blood units close to expiry between hospitals. This practise is currently undertaken by approximately one third of hospitals in England.

Traditional inventory systems are organized on a hierarchical basis with transportation flows from one echelon to the next [44]. More flexible systems also allow lateral transhipments, an example of horizontal collaboration, where inventory is shared between organizations on the same level in the supply chain. Lateral transhipments support organizations in dealing with demand variability and stock outs [45] and can lead to a more balanced inventory system [46]. In a recent review of the use of lateral transhipments in inventory management, 94 models were reviewed and classified [47]. Lateral transhipments to date have predominantly been used in the airline and spare parts industries and retailing as a means of maximising spare parts availability [48-49].

The idea of collaboration in the blood supply chain is not new; as far back as 1980, Kendall and Lee [50] discussed the concept of rotation and sharing of stock in this context. They developed blood rotation policies using a goal programming model for systematic redistribution of blood between hospitals with the aim of minimizing outdates and shortages. This is a highly mathematical approach which does not investigate the applicability or benefit of the method in the blood supply chain context. In an effort to do this Stanger et al [43] carried out a set of case studies with hospitals in the UK divided into two case groups, those who are currently sharing stock and those who are not. They found that the majority of the benefits highlighted in the extant literature (see [43]) are also relevant in the blood supply chain, although the specifics are often different due to the context. Stock sharing enhances the dual challenges of blood inventory management by reducing wastage, and hence unnecessary costs, whilst at the same time increasing availability, as hospitals can carry a wider range of units in their general stock. This increases the probability that a hospital will be able to meet demand directly from stock, reducing the reliance on ad hoc deliveries from the blood centre, avoiding delays and unnecessary costs. Whilst at the same time knowing that units can be transferred to a hospital with a greater chance of using the unit when it nears its expiry date, further reducing the risk of wasting the unit.

The general challenges of stock sharing are also relevant in the blood supply chain context. The study highlights two key factors which are of particular importance - cold chain validation and trust between hospitals. A reliable auditable cold chain with a fully visible audit trail for each blood unit is a regulatory requirement of stock sharing in the blood supply chain and as such is the key barrier to stock sharing success. The case studies show that the cold chain is not only a regulatory requirement, but also an important issue for transfusion professionals. In order to enable a stock sharing relationship trust between the hospitals is the ultimate enabler; all other requirements have proved to be of minor importance. Without trust between the hospitals the cold chain barrier cannot be 
redressed. In the extant literature although trust is discussed it is not seen as the key enabler, as in a commercial supply chain a defective product does not necessarily lead to impacts on safety of customers/patients [48].

The case studies demonstrated that, SOPs (Standard Operating Procedures) are essential for stock sharing relationships, to ensure that processes are executed correctly. SLAs (Service Level Agreements) set the framework for stock sharing agreements and provide the economic foundation for a successful relationship. Setting up and managing these procedures and agreements is both a barrier and an enabler to stock sharing in the blood supply chain, dependent on the perspective of the hospital. They are clearly an enabler to the smooth running of an existing stock sharing relationship. However, setting up SOPs and SLAs can be time consuming and requires staff to negotiate, set up and maintain these contracts. This initial effort can be seen as a cost which cannot be directly recovered and is therefore a barrier to those hospitals who are not already sharing stock.

Cross case analysis revealed a number of common themes which were discussed independently by several of the respondents. These were developed into eight common statements which are given in table 1. These statements formed the basis of a follow up survey which was sent back to the original interviewees; who were asked to rate these statements on a five point Likert scale. The survey results are shown in figure 2. Figure 2 shows that for statements $5-8$ which can be seen as the benefits of stock sharing, the two groups are in broad agreement that these are true. However for statements $1-4$, which can be seen as the barriers to stock sharing the two groups differ. Those who are not currently stock sharing perceive the effort in setting up agreements and procedures to be too great for the generated benefits, whereas the group who are currently stock sharing do not believe this to be the case.

Finally it is important to mention the role of government and regulation in reducing blood wastage. The WHO state that it is imperative that governments address blood wastage, with suitable regulatory oversight lacking in some countries [51]. This has led some governments to proactively work with hospitals on wastage reduction initiatives as is the case in Australia [52].

\section{Conclusion}

Good blood inventory management requires the need to maximise availability of all blood components at all times whilst minimising the wastage of this precious resource. Much literature over the last 50 years has studied this problem, however the majority has relied on complex mathematical formulations. However, work done in the UK in recent years has found that it is good management practises, including having good staff and training them well, coupled with simple inventory management practises and collaboration across the hospital which are key to good blood inventory management in hospitals. 
However, the blood supply chain extends beyond the hospital. Techniques from commercial supply chain management have be found to be useful tools for increasing efficiency across the supply chain. An example of this is stock sharing, where units close to expiry are moved from one hospital to another which has a greater chance of using the unit, reducing wastage of the system as a whole.

\section{References}

[1] Goodnough LT, Brecher ME, Kanter MH, AuBuchon JP. Transfusion medicine-Blood transfusion. N Engl J Med 1999;340:438-47.

[2] Reynolds $E$, Wickenden $C$, Oliver A. The impact of improved safety on maintaining a sufficient blood supply. Transfus Clin Biol 2001;8:235-9.

[3] Vamvakas EC. Epidemiology of red blood cell utilization. Transfus Med Rev 1996;10:44-61.

[4] Provisional report on notifications pursuant to Section 21 TFG (German Transfusion Act) for 2010. 2011. Accessed 08.08.2011, 2011, at http://www.pei.de/cln 170/ nn_155724/EN/infos-en/21tfgen/berichte-21-en/berichte-en/8-21tfg-report-2010-en.html

[5] Cobain TJ. Fresh blood product manufacture, issue, and use: A chain of diminishing returns? Transfus Med Rev 2004;18:279-92.

[6] Prastacos GP. Blood inventory management: An overview of theory and practice. Manage Sci 1984;30: 777-800.

[7] Nahmias S. Perishable inventory theory: A review. Oper Res 1982;30:680-708.

[8] Rock G, Åkerblom O, Berséus O, et al. The supply of blood products in 10 different systems or countries. Transfus Sci 2000;22:171-82.

[9] Annual Report 2009-10:Full Report. 2011. Accessed 15.05.2011, 2011, at http://www.bloodstocks.co.uk/pdf/ BSMS1.pdf.

[10] Millard DW. Industrial inventory models as applied to the problem of inventorying whole blood. Ohio State University Engineering Experiment Station, Bulletin No 180, Columbus, OH, March 1960; 1960.

[11] Silver A, Silver AM. An empirical inventory system for hospital blood banks. Hospitals 1964;38:569.

[12] Jennings JB. Blood bank inventory control. Manage Sci 1973;19:637-45.

[13] Brodheim E, Derman C, Prastacos G. On the evaluation of a class of inventory policies for perishable products such as blood. Manage Sci 1975;21:1320-5.

[14] Cumming PD, Kendall KE, Pegels CC, Seagle JP, Shubsda JFA. Collections planning model for regional blood suppliers: Description and validation. Manage Sci 1976; 22:962-71.

[15] Prastacos GP, Brodheim E. Computer-based regional blood distribution. Comput Oper Res 1979;6:69-77.

[16] Prastacos GP, Brodheim E. PBDS: A decision support system for regional blood management. Manage Sci 1980;26:451-63.

[17] Cohen MA, Pierskalla WP. Target inventory levels for a hospital blood bank or a decentralized regional blood banking system. Transfusion 1979;19:444-54.

[18] Owens W, Tokessy M, Rock G. Age of blood in inventory at a large tertiary care hospital. Vox Sang 2001;81:21-3.

[19] Chapman JF, Cook R. The Blood Stocks Management Scheme, a partnership venture between the National Blood Service of England and North Wales and participating hospitals for maximizing blood supply chain management. Vox Sang 2002;83:239-46.

[20] Rytilä JS, Spens KM. Using simulation to increase efficiency in blood supply chains. Manage Res News 2006; 29:801-19.

[21] Katsaliaki K. Cost-effective practices in the blood service sector. Health Policy 2008;86:276-87.

[22] Kopach R, Balcloglu B, Carter M. Tutorial on constructing a red blood cell inventory management system with two demand rates. Eur J Oper Res 2008;185:1051-9. 
[23] Perera G, Hyam C, Taylor C, Chapman JF. Hospital blood inventory practice: The factors affecting stock level and wastage. Transfus Med 2009;19:99-104.

[24] Chapman, JF, Hyam, C, Hick, R. Blood inventory management. Vox Sang. 2004;87;143-5.

[25] Stanger S, Wilding R, Yates N, Cotton S. What drives Perishable Inventory Performance? Lessons Learnt from the UK Blood Supply Chain. Supply Chain Man: Int J 2012;17:2:107-123

[26] Sirelson V, Brodheim E. A computer planning model for blood platelet production and distribution. Comput Methods Programs Biomed 1991;35:279-91.

[27] van Dijk NM, Haijema R, Van der Wal J, Sibinga CS. Blood platelet production: A novel approach for practical optimization. Transfusion 2009;49:411-20.

[28] Cohen MA, Prastacos GP. Critical number ordering policy for LIFO perishable inventory systems. Comput Oper Res 1981;8:185-95.

[29] Hariga M. Optimal inventory policies for perishable items with time-dependent demand. Int J Prod Econ. 1997;50;35-41.

[30]Tekin E, Gürler U, Berk E Age-based vs stock level control policies for a perishable inventory system. Eur J Oper Res. 2001;134;309-29.

[31] Fujiwara O. Perera, ULJSR. EOQ models for continuously deteriorating products using linear and exponential penalty costs Eur J Oper Res. 1993;70;104-14.

[32] Broekmeulen RACM, van Donselaar KH. A heuristic to manage perishable inventory with batch ordering, positive lead-times, and time-varying demand. Comput Oper Res 2009;36:3013-8.

[33] Sezen B. Changes in performance under various lengths of review periods in a periodic review inventory control system with lost sales: A simulation study. Int J Phys Distrib Logist Manag 2006;36:360-73.

[34] Raafat F. Survey of literature on continuously deteriorating inventory models. Oper Res Soc. 1991;42;27-37.

[35] Duan Q, Liao TW. Optimization of blood supply chain with shortened shelf lives and $A B O$ compatability. Int J Prod Econ 2014;153;113-129

[36] Chapman J. Unlocking the essentials of effective blood inventory management. Transfusion 2007;47:190S-6S.

[37] Yazer MH, Deandrade, DS, Triulzi et al. Electronic enhancements in blood ordering reduce component waste. Transfusion. 2015;56;564-570

[38] Stanger HW, Yates, N, Wilding R, Cotton S. Blood Inventory Management: Hospital Best Practise. Trans Med Rev. 2012;26;2;153-163

[39]Woensel TV, Donselaar KV, Broekmeulen R, Fransoo J. Consumer responses to shelf out-ofstocks of perishable products. Int J Phy Dist Log Man 2007;37;704-18.

[40] Dzik WH, Corwin H, Goodnough LT et al. Patient Safety and Blood Transfusion: New Solutions. Trans Med Rev 2003;17;3;169-180

[41] Levén E, Segerstedt A. Polarica's wild berries: an example of a required storage capacity calculation and where to locate this inventory. Supply Chain Man: Int J 2004;9;213-8.

[42] Hughes D, Merton I. 'Partnership in produce': the J. Sainsbury approach to managing the fresh produce supply chain. Supply Chain Man: Int J 1996;1;4-6.

[43] Stanger SHW, Wilding R, Hartmann, E, Yates N \& Cotton S. Lateral Transshipments: An Institutional Theory Perspective, Int J Phys Distrib Logist Manag 2013; 43: 747-767.

[44] Waters D. Inventory control and management, Chichester: Wiley; 2003.

[45] Evers PT. Hidden benefits of emergency transhipments. J Bus Logist 1997;18:55-76.

[46] [15]Diks EB, de Kok AG. Controlling a divergent 2-echelon network with transhipments using the consistent appropriate share rationing policy. Int J Prod Econ 1996; 45:369-379.

[47] Paterson C, Kiesmüller G, Teunter R, Glazebrook K. Inventory models with lateral transhipments: a review. Eur J Oper Res 2011; 210:125-136.

[48] Kilpi J, Vepsäläinen APJ. Pooling of spare components between airlines. J Air Transp Manag 2004;10:137-146.

[49] Kranenburg AA, van Houtum GJ. A new partial pooling structure for spare parts networks. Eur J 
Oper Res 2009; 199:908-921.

[50] Kendall KE, Lee SM. Formulating blood rotation policies with multiple objectives. Manag Sci 1980; 26:1145-1157.

[51] Access to Blood Products. WHO Drug Info 2013;27;1;3-5

[52] National Blood Authority, Australia. National Blood and Blood Product Wastage Reduction Strategy 2013-2017 (https://www.blood.gov.au/system/files/documents/nba-wastagestrategy.pdf accessed on 11/10/2016)

Figure and Table Legends

Figure 1: Hospital Wastage and WAPI 2012 - 2015 [Unpublished Data]

Figure 2: Summary of interviewees' responses to the survey questions [42]

Table 1: Statements derived from cross - and within-case analysis [42] 


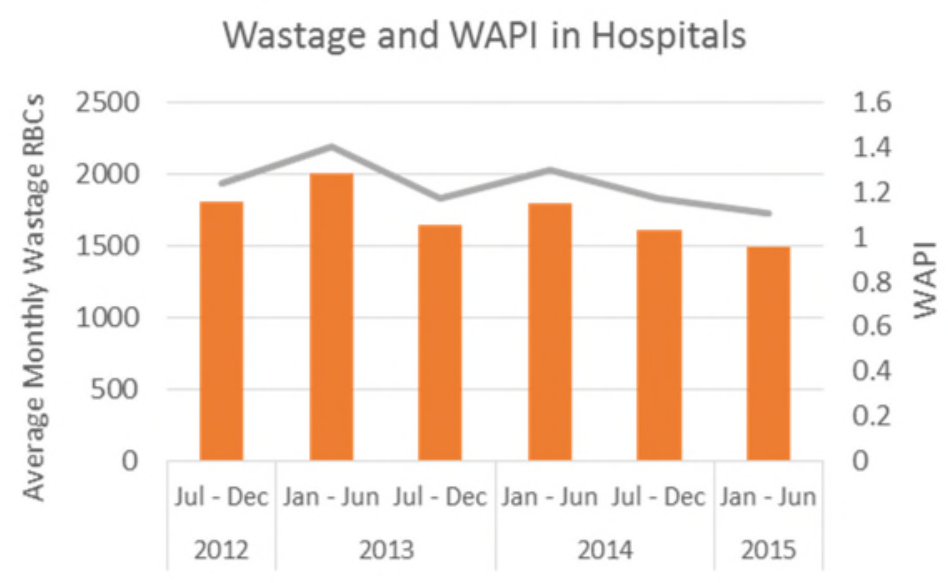

Source: NHSBT Data

Figure 1

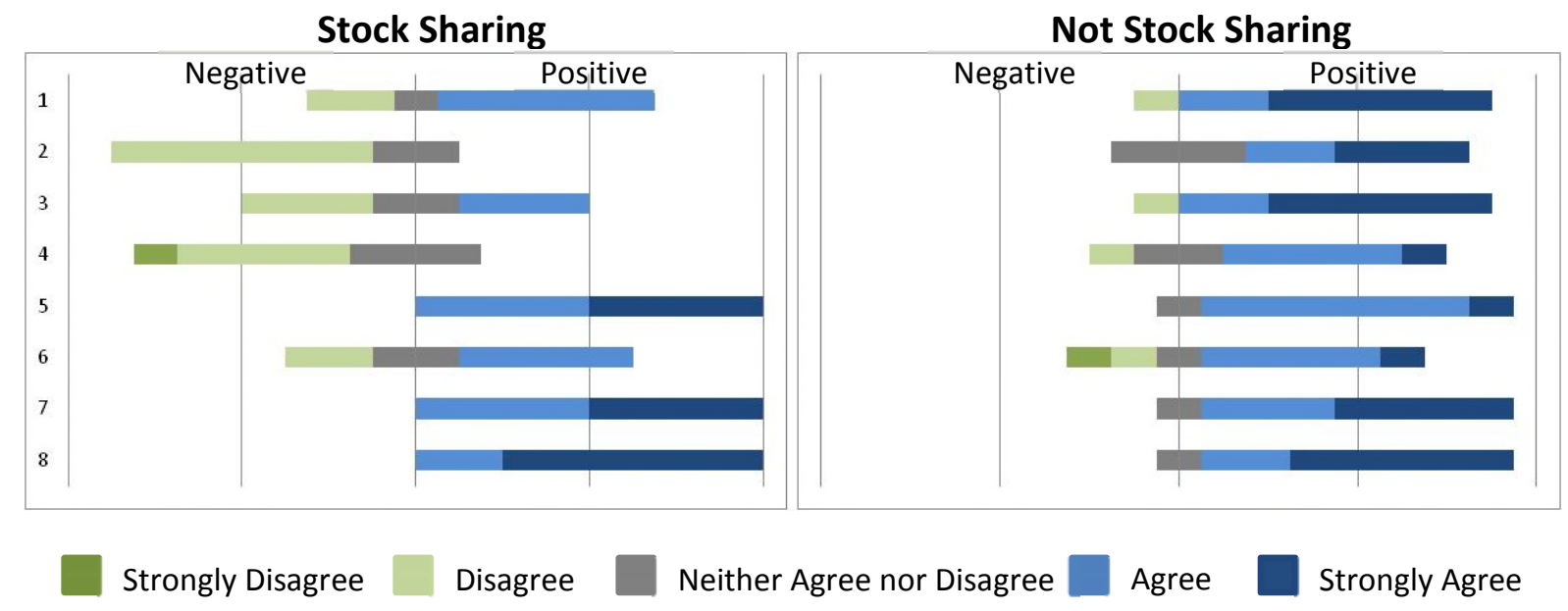

Figure 2

Table 1

Statement

1 The cold chain validation is a major inhibitor/barrier for sharing stock with another hospital.

2 The effort for setting up SLAs, SOPs and training staff outweighs the financial benefits gained through sharing stock.

3 Setting up a stock sharing relationship is time consuming and complex due to regulatory issues.

4 Transportation of units is a major problem for sharing stock with another hospital.

$5 \quad$ Stock sharing allows a more flexible management of blood stocks.

6 Stock sharing enables stocking rare types of blood/components.

7 The reduction of time expired wastage is a major benefit of sharing stock.

$8 \quad$ Trust between the hospitals sharing blood is essential. 